\title{
Looking Critically at ICT4Dev: The Case of Lincos
}

\author{
Manne Granquist \\ Malmö University $<\underline{\text { mne@ } \text { spray.se }}>$
}

\begin{abstract}
The following article is based on thesis research for the Communication for Development program at Malmö University, Sweden (Granqvist, 2003). It represents a study carried out through the NGO Funredes in the Dominican Republic, as a part of its Olistica project - an internet-based research "observatory" devoted to the assessment of the social impact of information and communication technology (ICT) in Latin America and the Caribbean 1 . The objective of the research was to contribute to a framework for the assessment of ICT-for-Development projects from a critical, social viewpoint. The study consisted of both an extended theoretical discussion on the social dimensions of technology and a case study from the Lincos project in the Dominican Republic.
\end{abstract}

\section{Introduction}

Appreciating the Social Dimensions of ICT in Development 1

The intention of the research (Granqvist, 2003) discussed below was to demonstrate how theoretical insights from critical social research traditions could inform the assessment of ICT projects in marginalized regions. While mainstream assessment models were (and are) devoted to infrastructure issues, and further fit well within a technologically determinist and often neo-liberal conceptual framework, alternatively minded movements have begun to explore more socially-oriented instruments. In order for such measures to form part of a cogent critical approach, an increased recognition of the social and political nature of technological development and design is imperative. Such a critical approach shares with the so-called 'post-development' tradition (Rahnema \& Bawtree, 1997; Saunders, 2003) a skeptical stance towards established development thinking. Power relations, particularly between 'developers' (development agencies, experts, governments) and 'developees' (marginalized communities) ought to be the focus of attention, instead of neglected (as is typically the case in mainstream assessment models).

In order to discuss the role of technology and technological discourse in the maintenance of such power relations, the thesis drew from different theoretical streams of thought. As an entry point, four "social dimensions" of technology were identified; social embeddedness, the design process, usage, and political context. These abstractions were meant to bring to light aspects of technology that are rarely acknowledged in the dominant discourse. The two first categories, in particular, were brought up to counter the common understanding of technology as a neutral tool, and bring attention to its historicity and political workings.

The 'social embeddedness' of technologies is a concept debated in Science \& Technology Studies (STS), which, put simply, refers to the values "built into" a technology (Escobar, 1994; Pfaffenberger,

1 http://www.funredes.org; http://www.funredes.org/olistica 
1992). Current STS theory, but also classical Critical Theory and feminist research inform discussions on how such social embeddedness may be dealt with and assessed. In terms of the design process, the Scandinavian Participatory Design tradition presents us with a movement of systems designers whose members were among the first to recognize the political character of technological design (see, e.g., Bjerknes, Ehn, \& Kyng, 1987; and Ehn, 1988). These scientists made common cause with industrial workers rather than with management when designing workplace information systems. Their legacy is particularly instructive for a critical approach to technology in the development context, where conflicts of interests similar to those of workplaces prevail. Richard Heeks' (1999) critique of the "tyranny of participation" provides a further source of inspiration for this section, stressing the need to be cautious about 'cosmetic participation' as the concept of participatory development increases in popularity.

The third category, usage, was (and is) the one where socially-oriented theorists and practitioners, such as the Olistica network, had come the farthest; and the discussion here was informed by current debates among NGO's, grassroots groups and activists devoted to this area (e.g. Mistica, 2002; Menou, 2001). Issues such as equitable access, local content production, and socially meaningful usage were emphasized. The last concept, the political context, differs from the others in that it was not regarded as an analytical category in itself, but rather as making up the framework of the other three and providing them with meaning. Bringing it up as a 'social dimension of technology' served to highlight the importance of contextual analysis and the need to politicize every instance of assessment, focusing on how different aspects of ICT projects relate to broader relations of power. A critically-oriented assessment approach could be rewardingly informed, it is argued, by the perspectives of dependency theory and postdevelopment thinking - research traditions which have attended to the power structures of the development domain and emphasized the continuing role of economically dominant societies in perpetuating the conditions of marginalization.

The notions of social embeddedness, design process, and usage would thus serve as analytical categories when examining the Lincos project to appreciate the theoretical discussion's relevance and applicability in the field. The various issues debated under each category became "investigational themes" that would guide the observation of the Lincos case. The theoretical framework was not regarded as a completed intstrument and the case study did not set out to arrive at a formal and conclusive assessment regarding the Lincos project. Rather, the aim of both was to offer some new perspectives and demonstrate their relevance in an actual ICT-for-Development experience. The expectation was that this work could form part of broader strivings towards more structured social assessment models, based upon a critical social perspective. The remainder of this article is based on observations from the Lincos project.

\section{Background}

\section{The Dominican Republic}

The Dominican Republic is a country of nine million inhabitants, located in the Caribbean Sea between Cuba, Jamaica and Puerto Rico, on the island of Hispaniola, which it shares with the Republic of Haiti. The Dominican Republic, which, following Columbus' arrival in 1492 served as the lead settlement of the Spanish colonization of the Americas, gained its independence in 1865. Since then - similar to other Latin American countries - the nation has been plagued by an array of infamous dictators, high levels of political corruption, dubious invasions by the United States and, as a result, widespread human calamity. Of the population, of which the vast majority are descendants of Africans that were enslaved by the Spaniards, around thirty to forty percent live in "poverty" (according to the World Bank, 2002).

About half of the workforce is formally unemployed (World Bank, 2002) and for those who manage to obtain a job, salaries are minimal. Four out of five large businesses are owned by foreigners, predominantly North Americans and Spaniards (Howard, 1998), many of whom exploit the economic conditions of the "Zonas Francas" - the free trade zones where foreign companies escape taxes and pay minimum salaries for repetitive labor during twelve-hour working days. Others own large plantations, where Haitian immigrant workers are employed in what has been labelled "modern slavery" (Latortue, 1999). Although the country is a primary exporter of agricultural products such as sugar, coffee, tobacco and fruits, only a minority of the population have access to participation in the wage economy. Dominican politics 
traditionally caters to the small but very wealthy economic and political elite, and social welfare is practically non-existent. Past and current conditions have caused over one million Dominicans to flee the country - the largest diaspora in the world in relation to the size of the mother country (Howard, 1998).

In the year 2000, Hipolito Mejía of the Dominican Revolutionary Party, took over the presidency from Leonel Fernández of the Dominican Liberation Party, after winning the election on a program that promised to eradicate corruption and improve the situation of the poor. Mejía soon proved incapable of removing corruption, however, and despite initial promises to the contrary, his economic strategy for the nation drew to a large extent on a neo-liberal (free market) agenda. Nevertheless, Mejía's government had at the time of this study initiated a widely proclaimed "Plan against poverty" and many Dominicans believed that Mejía was launching a serious attempt to improve the situation of the country's marginalized communities, although discontent was beginning to spread. The plan included inititatives concerning infrastructure, education and attempts to extend the use of ICTs in the nation. These latter projects are typically sponsored by the telecommunication industry and include a computer lab initiative for schools and technological community centers such as Proyecto Ave2 as well as the Lincos, which will be discussed more comprehensively below.

For this study, five Dominican communities that had received a Lincos center were visited during a three-week period. This time was divided between one community chosen for in-depth observation, another chosen for comparative observation, and shorter visits at three other Lincos sites. Interviews were conducted with Lincos staff members, Lincos community committee members, Lincos users, ordinary community members, village politicians and the director of the Dominican Lincos project. Meetings and classes were attended and the researcher also conducted direct participant observation as an ordinary Lincos user. In addition to these field impressions, official Lincos documents were analyzed. The objective was to gather a multi-faceted impression of the Lincos experience. The selection of persons for interviews, and locations for observation, was aimed towards broad representation rather than being formally randomized. The process was an evolving one, in which selections were made during the course of the investigation, combining a non-probability "subjective selection" (interviewees and observation sites are hand-picked) with a "snow-ball selection" (one experience leads to another) strategy (Denscombe 1998). Interviews and observation were carried out more in a journalistic format than that of traditional research with the overall objective of obtaining a rich and multi-dimensional image of the Lincos project.

\section{The Lincos Project}

The Lincos project was an initiative launched by Entebbe, a Costa Rican foundation3 founded and directed by Jose María Figueres, former president of Costa Rica and a former military engineer. Although Entebbe engaged in other development projects, particularly related to environmental issues (reflecting Figueres personal engagement), Lincos - which stands for "Little Intelligent Communities" - was the organization's flagship. The Lincos project was carried out together with a host of cooperating actors, mainly representing business and academic institutions. The Massachusetts Institute of Technology (MIT) and the Instituto Tecnológico de Costa Rica, on the academic side, and Microsoft and Hewlett Packard on the business side, were among the most prominent partners. Altogether, some two hundred different institutional actors were engaged in the project.

The Lincos initiative started its implementations in Costa Rica in 2000, with the intention of eventually going international on a large scale. In the end, though, the Dominican Republic was the only other country to which the project was exported. The government of the Dominican Republic closed a deal with Entebbe for the installation of sixty Lincos stations throughout the country, as a part of president Mejías Plan against Poverty. The idea was to have these installed by the end of 2002, on a budget of 60 million US

\section{$2 \mathrm{http}: / / \mathrm{www}$. proyectoave.com.do}

3 The organization is known formally as La Fundación Costa Rica de Desarollo Sostenible ("The Costa Rican Foundation for Sustainable Development"). The shorter name, Entebbe, is borrowed from the name of its founder's residencial area in Costa Rica (Hoffman, 2002). As of 2005, and the writing of this article, the organization seems to be rather inactive. The Lincos project is apparently deteriorating, as demonstrated by its webpage which has not been updated for some two years. 
dollars4 (Lincos website5, newsletter March 2001). The number of Lincos sites were later reduced to thirty. A government office in Santo Domingo (the Dominican capital) called "Pequeñas Comunidades Inteligentes"6, with around thirty employees, was in charge of the project in the country. Entebbe was responsible for delivering the centers and upgrading them, providing training to their workers, and overall development of the project.

Half of the thirty centers had been installed at the time of this study and the government had decided not to continue the collaboration with Entebbe for the remaining fifteen, which were to be realized instead under the supervision of the Dominican Ministry of Education. The cost of installing each unit was 2.8 million Dominican pesos (appr. 130000 US dollars in 2003). This price did not include the administrative costs of either the central office or the individual units. A monthly budget of 25000 pesos (approximately 1 100 US dollars) was allocated for the maintenance of each center, intended to cover salaries, as well as running costs, such as electricity and purchases.

According to the information provided by the Dominican Secretary of State, the principal objective of the project was to "attain sustainable human development in the selected communities, through processes of learning supported by a variety of technological tools; contribute to the elimination of the so-called technological divide; and guarantee that these remote communities have the same opportunities as other, more developed communities". A further purpose of the implementation of the project was "to make these groups of people from very poor communities with serious limitations advance as individuals, emphasizing education, health and a harmonious relationship to nature" (Lincos web page and information brochures, author's translation). 7

\section{What is a Linco?}

What exactly is a Linco? The answer to that question actually shifted during the course of the project's implementation. Until shortly before the case study was carried out, the Linco was equal to a very specific concept - an industrial container, redesigned and filled with computers and a range of other high tech equipment. For reasons that will be discussed below, however, the container concept was eventually abandoned in favor of ordinary concrete buildings, with a set of rooms throughout which the equipment was distributed. This development meant that at the time this study was carried out, there existed two types of Lincos. The two Costa Rican ones, as well as the first five of the Dominican ones were metal containers; while the ten most newly built Lincos in the Dominican Republic were installed into ordinary houses. Three of the five Lincos sites visited during the study were of the container variety. However, the old containers were gradually being phased out in favor of houses (as Dominican authorities took control of the project from Entebbe) and the different sites would soon all be of a similar appearance. At the time of the study only one of the Lincos in Costa Rica was in service.

The Lincos units all had a similar initial set of equipment:

- A set of Pentium II/III PC's (5-6 in the containers, 10-14 in the new buildings)

- Each computer equipped with a 15" screen, audio speakers, CD-ROM, and diskette station

4 The accurateness of this figure is unclear, as is the contents of this alleged budget. Another newsletter confusingly even mentions an(other?) investment of $\$ 180$ million (October 2001). The Director of the Dominican administration of the project claimed to never have heard of either of these amounts when interviewed. See below for further discussion of official financial circumstances of the project.

$5 \mathrm{http}: / / \mathrm{www}$.lincos.net. All referenced newsletters are published on the website and were verified in June 2005.

6 "Little Intelligent Communities"

7 Taken from the Lincos website (http://www.lincos.net). Entebbe's declared mission for the Lincos project was expressed slightly differently, as follows: "To help communities in disadvantage from developing countries to intelligently access and use a series of services and applications such as: Telemedicine, Internet, Electronic Communication, Videoconference, Electronic Trade, Educational Computer Science, etc., within the training setting of the target population. As a result, these communities will be able to take a remarkable quality step in their development process and become Little Intelligent Communities, 'LINCOS'. 
- 1 Laser printer

- 1 flatbed scanner

- 1 server computer

- Internet access through a VSAT satellite mounted on the roof

- 1 Fax/Copy machine

- 1-4 satellite phones

- 1-2 television sets with VCR and DVD players

- 1 VHS Camera

- 1 digital still camera

- 1 "telemedicine kit"

- 1 instrument for water and soil analysis

- A radio transmitter

Most of the hardware was produced by Hewlett-Packard, and the majority of the initially installed software had been provided by Microsoft. The latter included the operating system (MS Windows 98), and the office package (MS Office), plus several other programs (MS Encarta, MS Money, Age of Empires, etc.). Additional software came from LCSI, another project sponsor, which produces educational software and contributed their programs "Micromundos" and "Mi Isla de Fantasia"8 to the project.

\section{Lincos \& Social Embeddedness}

In considering the social embeddedness of technologies in this research, a set of identified issues suggested guidelines for the assessment of ICT projects. A critical social assessment should examine what type of usage different technologies allow, which behaviors they prompt and what social values they tend to reproduce or confront. A critical assessment effort should seek to reveal, although not exaggerate, the political significance of this embeddedness. As a further task, the critical investigator should draw attention to the prospect of alternative designs. Following are some observations from the Lincos project with reference to these issues.

\section{A Box from the Sky}

As mentioned, the units making up the first set of Lincos were accommodated in industrial metal containers and five such containers existed in the Dominican Republic at the time of the observations. Three of these were visited during a phase when they were about to be exchanged for ordinary concrete buildings. In all three sites, workers and users expressed serious dissatisfaction with the containers. At one of the sites, the Lincos staff had been on strike for six months because of the unbearable tropical heat in the metal containers, which lacked air-conditioning and proper ventilation. At another site, all computer classes had been cancelled, awaiting the inauguration of the new concrete building, partly due to the heat conditions and partly because of the limited space available in the containers - only five to six uncomfortably seated students could fit into the tiny room, making it impossible to share computers between two persons, and leaving only minimal space for a teacher. The designers of the containers initially included a giant, pole-mounted awning above the container to cover it from sun (and rain). The Lincos staff soon experienced problems with this expensive add-on accessory, however, as it had to be taken down in the event of a threatening hurricane, or to be cleaned, and it could not be mounted again by the regular staff.) At the time of the visits, none of the site containers were protected from the sun by this or any other means.

Power shortages are very common in the Dominican Republic - most villages experience daily, several hour-long interruptions - and when they occur, the Lincos staff must resort to the container's small power plant, which runs on gas and is extremely costly. One of the Lincos sites was simply closed down during power shortages, because of the inability to cover the gas costs with the limited financial funds available

8 The English titles are "MicroWorlds" and "My Fantastic Island" respectively. 
through the project9. On their web page, Entebbe had declared that the units would be supplied with solar panels (Lincos newsletter, November 2001), which would both increase self-sustainability and be consistent with environmental awareness (particularly since the Dominican electricity system relies on imported petroleum).

The newsletter even indicated that the required technology had already been developed by the Lincos team and that it would be installed within a short time at the Dominican Lincos units. By the time of this study however, none of the sites had been so equipped. A Lincos staff member in one of the communities commented 10: "The bosses, when they were here during the inauguration, they said they'd bring twenty solar panels, but no.... [...] Politics, you know, they talk and talk". According to Luis Veras, then the director of the Lincos project in the Dominican Republic, there existed no plans to carry out this work, except possibly in those communities that were not covered by the national electricity grid.

A further drawback of the container concept was expressed by Mr. Veras, when explaining why it was eventually abandoned: "The container creates the concept of temporariness; the people do not regard it as rooted in the community". While a container may imply some advantages when transporting the project to the remote communities ("it may even be transported by helicopter" according to the Lincos web) its value as compared to relatively cheap local constructions may certainly be questioned. As one observer commented, "[i]n practice, the mobility characteristic of the containers is irrelevant, since their final destination is the stationary implementation in one site" (Hoffman, 2002, author's translation). In addition to indicating temporariness (and transience), the containers also give the clear impression (in this case wellfounded) that the project has been developed externally and brought to the community in a top-down manner as a wrapped-up "development package". As one Olistica member who visited a Lincos container concluded, this concept is certainly not helping to demystify the technology or to integrate it into the community 11 .

The container idea was at the center of the marketing of the project - an image of the container was even included in its logo. In a sense, the container was crucial for the Lincos project, something that was demonstrated by the fact that there was hardly any mention on the Lincos web page about the Dominican administration's decision to abandon the unsuccessful concept (where it was mentioned, the limited space was the only declared reason for the decision). The logo and website including the container image continue to appear, suggesting that despite the negative experience in the Dominican Republic the use of the container remains a key element in Entebbe's overall Lincos marketing strategy.

A reasonable assumption is that the container concept was developed partly as a marketing strategy. While for the people of the communities, the design was more or less disastrous, for other persons, the same design may be seen as successful, particularly for the Lincos officials. "They have their reality, we have ours", one of the striking staff members commented appositely, referring to those responsible for the design of the container. One understanding is that the interest of the Lincos officials, eager to develop a marketable product, has taken precedence over the interest of the community members.

This small metal box, crammed with state-of-the art technology, obviously signals modernity and inventiveness to potential sponsors, buyers and reporters. Articles about the Lincos project have been overwhelmingly enthusiastic (as a search on the web would show), and evidently, Lincos fundraising has been highly successful.

The Dominican Lincos administration's decision to switch from the container to ordinary houses was significant. The heat was no longer a problem and the space of the sites was obviously much greater. The power plant solution was replaced by generators, which stored electricity from the ordinary power grid onto a set of batteries to be used during shortages, thus avoiding reliance on expensive gasoline. The buildings, looking like ordinary houses and built in the community, rather than constructed in a foreign country and then transported there, presumably also had an effect on the experience of affiliation among community

9 As mentioned above, one of the other two sites visited was entirely closed down and since only a short time was spent at the third one, there was no opportunity to investigate if the same was occurring there. 10 When not stated otherwise, all quotes (presented anonymously as to indiviudal and community) in this section are from interviews and chats with community members of the five sites visited.

11 Personal Communication. 
members. It was noted during the observations that the Lincos houses were frequented far more often than their container equivalents.

\section{One Size Fits All?}

The concrete buildings shared one aspect with the deserted containers. They were a ready-developed concept, thought to apply equally well to all the different communities involved in the Lincos project. Minor differences existed, specifically between the three different "batches" (units were built five at a time, with several months and a new contract with Entebbe between them), but basically, the architecture was one and the same in all of the communities. An appointed community committee, as well as the local Lincos workers, did have a say in how to fit up the building once it had been built, but they did not participate in designing it. While this remains true of most architectural projects around the world, it certainly perpetuates the image of the Lincos project as a "one-size-fits-all" model, developed externally to be subsequently brought to non-participating communities.

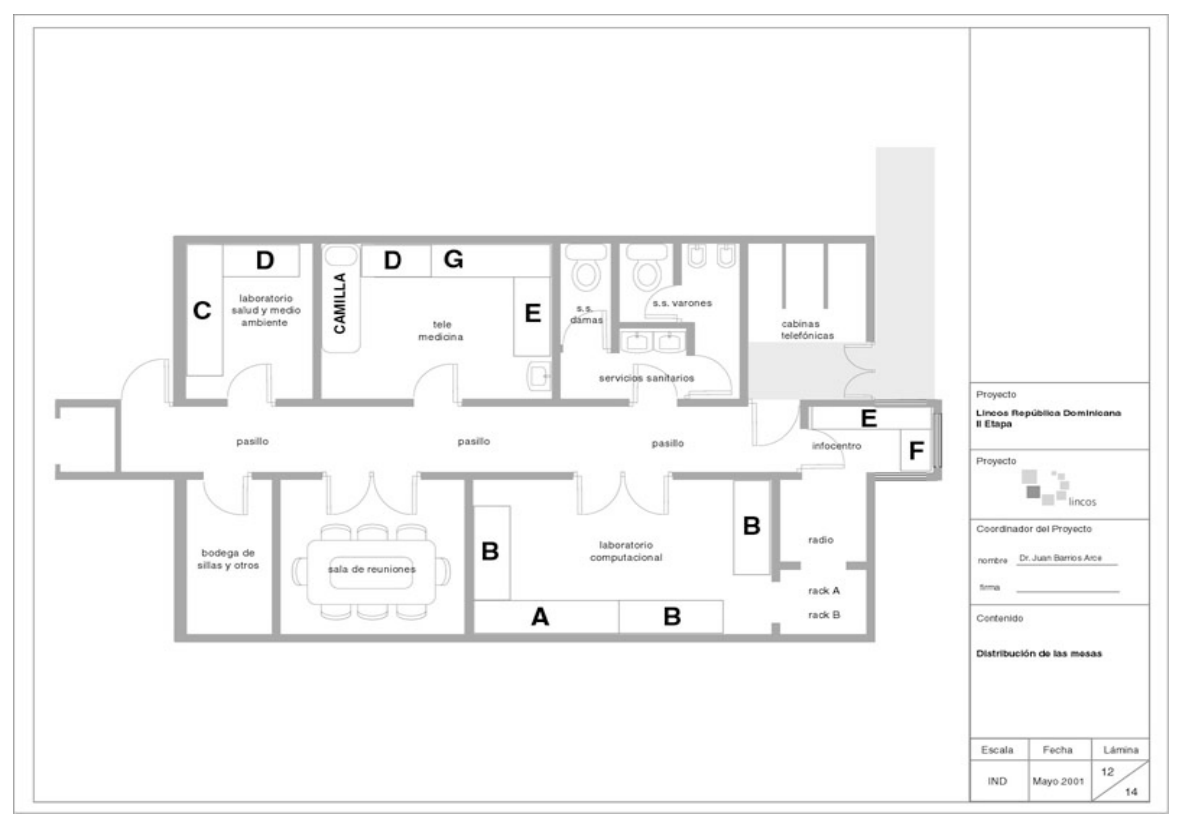

Figure 2. Architectural solution shared by all new Lincos sites. (from internal Lincos document)

Although Lincos' Director asserted that "no two containers are the same"12 - a statement for which little support was found - uniformity was manifest in many aspects. Just like the architecture and the design of the container, the ICT equipment was similar at the different Lincos sites. A similar set of information technologies was thought to be suitable for all the communities involved in the project. As one unimpressed observer remarked: "Like a Swiss army knife with 23 functions, Lincos offers a fascinating technological potential, suggesting that with this the recipients are prepared to address any type of underdevelopment problem" (Hoffman, 2002). What was more problematic than the fact that they were all the same Dominican rural villages do indeed share many conditions and needs - was that the uniformity reflected the fact that the technology had not been adapted to the circumstances of the users, neither in its choice nor in its design. While the Lincos website claimed that the technology was selected according to the needs of every individual community, the Lincos office in Santo Domingo distributed similar brochures for local Lincos communities, in which exactly the same set of technologies was listed.

\section{"No Comprendo"}

12 Interview with Lincos director Juan Barrios - "El tercer mundo en línea". http://centralamerica.ms.dk/articles/Spanish/enlinea.htm 
To varying degrees at different sites, the software, the manuals and even the keyboards of the Lincos were in English. At some of the sites, even the Windows version was English. There is most certainly reason to wonder why, since both the software and the manuals used, as well as keyboards, are produced on a large scale in Spanish. Whatever the reasons for this mistake, it certainly had implications for the users at the Lincos sites, where there was virtually no one with proficiency in English. In one village, the scanner and the video camera had never been used until an American visitor was able to interpret the instructions for the potential users.

\section{Summary}

This section has illustrated the relevance of the social embeddedness of technologies in the Lincos case. The technologies involved in the Lincos project - and in any other technological experience - through the way they were chosen, designed, marketed and understood, all have different social implications for the members of the user communities and for other stakeholders.

Further, as demonstrated in the case of the Lincos container, different technological characteristics are of different interest for different persons and may also be interpreted quite differently. A critical investigator has to examine the experiences of those persons or groups whose situation she is concerned by, while also contrasting those experiences with conflicting ones. In the cases above, the social implications of the design have been interpreted from the viewpoint of the community members as a group, and to some extent compared to that of the project's management (also as a group). In many situations it may be of equal interest for a critical assessment effort to investigate differing experiences between community members, drawing attention, for instance, to the way specific designs affect women in comparison to men.

\section{Lincos \& The Design Process}

In our work elsewhere on the design process (Granqvist, 2003), a series of themes and their significance for the social world of users and community members was discussed. Crucial issues include whether or not the users are actively involved in the planning, creation and evaluation of technologies, and under what circumstances; to whom the process is open; how it is affected by socio-cultural structures; and whether participation is cosmetic, rather than empowering. Also important is the extent to which an ICT project builds upon local knowledge and the viewpoints of marginalized citizens. Recognition should further be given to the role of the designers: whether they act primarily as technical experts; to what extent they share everyday life with community members; and to what extent their understanding of the problem is allowed to guide the process.

In the Lincos case, several of these issues were rather simple to deal with - participation was close to nonexistent and the design process did not even take place within the borders of the country. With its uniform design and lack of participation, the Lincos project appeared as the archetype of a "solution in search of an application". No part of the Lincos project had been developed on a local level. Instead, a host of institutions from different countries had been involved in developing everything from the container and its contents, to the "methodologies" intended to be used inside them.

\section{Lincos Coming to Town}

Let us start with the actual decision of bringing a Linco to a community. Juan Barrios, Entebbe's Lincos director asserted that the establishment of a Lincos unit in a community was "always realized upon the initiative of the people themselves" 13 . There are clear difficulties with this statement since it is almost

13 Interview with Lincos director Juan Barrios - "El tercer mundo en línea" http://centralamerica.ms.dk/articles/Spanish/enlinea.htm 
without exception the case that it is a decison of the funder (in this case the government of the Dominican Republic) as to where such projects are implemented 14 .

It is true that the government, once it had decided on a proper location, did turn to the local authorities of the community in question before having the Lincos installed. "They did introduce the project", as one community member explained, "but speaking only to the important persons, without reaching the mass of the people". Further, as is common for these types of projects (cf. Benjamin \& Dahms, 2001) - the communities were not offered any alternatives to the project. They might indeed turn it down, but were hardly likely to do so because the project would then simply go to another community instead. "It was like a lottery draw", one Lincos staff member remarked. A community committee member explained it as "a battle between two communities".

While the initiative resided with the government, rather than with the communties (as claimed by some Lincos officials), the centers were certainly accepted by the communities before being installed. In these cases, however, the community was represented by politicians with no other options from which to choose.

In relation to the subsequent installation of a center, a town meeting was held, to which all interested community members were invited (reportedly some 50-300 persons showed up in the various communities out of a population range of 5-10 000). At the meeting, at the initiation of "the high-up persons of the central organization of the project" (as one committee member put it) a community committee was elected to supervise the Linco. This committee consisted of fifteen persons and was the key to the community's influence over the center. By decision of the Lincos administration, nine of these were those with important positions in the community - the mayor, the elementary and high school principals, a representative from the Catholic Church and others. The remaining six committee members were elected by the meeting attendees, and also tended to be village members with significant social standing. Notably, the committee that was now supposed to guarantee the community's involvement in the project, had a membership that was not only delegated by the government, but also, as Heeks (1999) has put it with reference to these types of projects, "skewed towards the powerful and away from the marginalized". Moreover, committee members were non-users, or at least they were not chosen because of their status as users but rather because of their (high) social status.

In addition, the committee, whose members received no payment, was not formed until after the installation of the center, drastically limiting community influence over the design process. This was true for the first container Lincos as well as the subsequent concrete house Lincos, where the staff confirmed that the committee was appointed some three months after the start of construction of the building.

\section{Lincos Evaluation - Cries and Struggles}

Additionally, there existed no formally structured evaluations undertaken by the community members. The assessments that were made were carried out by visiting Lincos officials. Although the containers were finally replaced in the first set of Dominican Lincos communities, this was happening only after some three years, implying a very slow and non-interactive response process.

As one staff member expressed it, "It was a cry from us, the local coordinators". In another community, no one was using the telephones because there was a Codetel15 office nearby, where clients could receive calls instead of just making them (and pay with coins instead of prepaid phone cards). A staff member commented: "We have struggled for a telephone with which we can receive phone calls, to send messages to the villagers so that they come here and return the calls. It hasn't been possible. We don't know the reasons. We don't know." This person was still very positive about the project, but in his choice of words, one might get a sense of the nature of the relationship between the community members and the Lincos officials.

14 If there are any doubts, the dissemination of the units makes the case clear; out of 27 planned and realized units at the time the study was conducted, 23 were located in the westernmost part of the country, in the border regions currently prioritized in the government's development efforts.

15 A national phone company 
Even Mr. Veras, the head of the Lincos office in Santo Domingo, recognized the fact that the design process failed to take into account the local situation: "The container was designed with Costa Rica in mind. Costa Rica is much chillier than here", he admitted.

Additional issues with the units are suggested by the fact that several installed applications were never used. Neither the telemedicine equipment nor the water and soil analysis kit, both widely referred to by the promoters of the project (and a basis for the image of Lincos as being of wide-ranging social benefit) had ever been used in any of the communities visited, with only a few exceptions for testing purposes. As well, the videoconference system was seldom or never used ("who would we videoconference with?"), as was true for an array of the installed software (particularly that which was only available in English). Except for a few commonly used services (see below), fact was that most communities still wondered what they were supposed to do with their Lincos. The whole experience might be best summarized with an excerpt from an interview with a community member:

In the case of the Lincos projects...there was no real introduction. They didn't tell the people first, before bringing the project, instead they came with the project first and then they spoke to the people. The first thing should be to speak to the people, 'we're bringing a project, and we're bringing it to show you', speaking to different sectors.... that way they will know what the people think, 'well, we're going to modify this, we'll drop this thing that the people are not interested in'... The obvious consequence of this is that the people didn't give their support, they didn't attach importance to it, and with time the project diminishes, it won't be growing, because the people don't regard it as useful, because it doesn't have any importance for them, it doesn't have any value $[\ldots]$. The consequence is fatal, very negative, and then the project is lost.

Thus, the organization of the Lincos project did not only exclude users from participating on any level of the design process, but also kept them from taking part in the planning and introduction of the project, failed to provide a structure for evaluation, and neglected local knowledge and understanding of the local situation. As noted above, to the limited extent that community members were involved, membership was biased towards the already powerful, and actual users were not generally included. The design team whose members appeared not to have visited the communities, let alone shared their everyday life - had sole responsibility for both defining the problems and working out the solutions, which in practice meant that "solutions" and implementations were the same for all communities.

The consequence was, that, out of a host of expensive technologies, only a handful were used to a reasonable extent, and the services they provided could have been supplied equally well by much less costly telecenters. Moreover, the development of the technology had not formed as part of a strategy in line with community members' own visions, and decision-making had taken place above their heads. Consequently, people generally did not feel affiliated with the project and expressed indifference or, as in the case of some staff members, even frustration towards the project. The apparent attitude of Entebbe when it comes to these matters is perhaps best expressed on their own webpage: "With an adequate process of technological transference", it was predicted, "the individuals will accustom to the applications when they become adapted to the unit".

\section{Lincos \& The Usage of ICTs}

At the Lincos sites visited, activities were concentrated on mainly three services: computer classes, websurfing and e-mailing, and photocopying. At the occasional site, the radio transmitter was also used extensively. Other services that the centers offered, including telephones, seemed to be used only to a very limited extent, or not at all.

\section{Access for All?}

The Lincos case - like most other ICT-for-Development efforts - succeeded in bringing ICT access to people who had previously lived without it. Not only computer technologies, but also public phones now became available to people who had been excluded from the use of such equipment before. Observations at the Lincos sites further confirmed that use was relatively equally distributed between men and women, and 
between different age groups. There were obstacles however, that prevented some citizens from participating. In the case of Lincos, the charges applied to the services would appear to be the primary reason for such restriction.

In the Lincos case, serving villages with official unemployment rates of over seventy percent, the attendance in classes was quite high, even though the charges applied very likely excluded a large proportion of the population. Lincos' prices were not high compared to those of other similar services; rather the opposite16. Nonetheless, even relatively low prices exclude the poorest parts of the population from participation.

While monetary charges were probably the most common factor of exclusion, others may have existed as well, apart from those already mentioned (the lack of Spanish manuals and the unbearable heat). These might include the formal "terms of usage" which declared, among other things, that users were not allowed to "make politics" when using the computers. Further it is notable that during the period of this study, no member of the Dominican Republic's largest immigrant group, the Haitians, was observed as visiting a Lincos. This may be due to the issue of charges (Haitians make up the poorest part of the population) or to deeper issues of Dominican attitude towards Haitians.

In response to these issues, according to several Lincos staff members, scholarships existed for children whose parents could not afford their computers courses. It should be noted, however, that these scholarships were donations from private persons or local businesses, rather than strategies initiated by Lincos or the other project sponsors.

\section{Autonomy \& Empowerment?}

With respect to local content or program development, this was very limited at the Lincos sites, and the result of individual rather than project-based initiatives. Students used word processors to do their homework, others wrote résumés and occasionally individuals would hire the digital camera to take wedding pictures. In one village an employee at the Linco used the video camera to make an educational film about the environment that he intended to show to young people for educational purposes. Notably, in those communities where the radio transmitter was functioning, it was actively used. Although most of the material transmitted was commercial music, the shows were created locally by, and for, the community itself.

The computer classes used software, most of it coming from a single producer, which was taught with the help of structured, written instructions, telling the students exactly what to do. The teachers seldom had much more computer skills than their students. Notably, these classes stood in sharp contrast to the marketed educational vision of Lincos officials, according to which the technologies were used in exploratory and independent ways to accomplish communitarian ends in the community (see, e.g., the Lincos website; and Badilla, 2001).

Many persons expressed content with the fact that they now had access to new information. "Now we can look for facts about any issue", one person explained when asked to describe the benefits of the project. "For example, [...] when the problems with Bin Ladin began [...] I was interested in finding out who Bin Laden was [...] and I searched the Internet and I found out who he was". However, there was little concern expressed with regard to the validity of sources nor of the assumptions or political positions which underlie much of this information.

In cases such as Lincos, where the government is in charge of the project, there is reason to examine whether the available communication tools can be used to support strategies for increasing the political influence of marginalized people. Certainly it would seem that this was not a concern in the case of Lincos. Although the project was a part of the government's efforts against poverty, neither this nor other projects seemed likely to threaten existing political relations or resource distribution. Not only did people not seem to be given training or assistance in using ICTs to increase their political influence, in this case they seemed to be expressly forbidden from doing so. Communicational activities were primarily carried out on an

16 To use the Internet cost 10-20 pesos (\$0.50-1) for an hour, and computer courses were 50 to 100 pesos $(\$ 2.50-5)$ per month. 
individual level; people used the e-mail for keeping in touch with friends and relatives, and chat rooms on the Internet were used for recreation rather than as a means to achieve greater social (or political) influence or participation.

\section{Maintenance}

Another theme to which attention might be drawn is that of the maintenance and workings of an ICT project, and whether it creates self-reliance or dependency. The impression from the Lincos case was that Lincos management tended to give responsibility to the individual centers while at the same time restraining their potential for self-reliance. In Lincos official material, it was stressed that it was up to the community to make the most of their Linco, yet they were given hardly any resources to do so. Each community was allocated 25000 pesos (approximately $\$ 1.100$ ) to cover their monthly expenses. The income from the services the Lincos provided could be added to that as revenue, but that amount was typically very small. After salaries had been paid, there was seldom much left. Lincos staff members reported that they frequently had to wait up to two weeks before being able to purchase such things as paper and toner.

Money was not the main problem, however. Most of the sites visited in this study experienced problems with the technologies. At one center, the Internet connection was down for a month, at another the telephone never worked, and at several there were problems with the computers. When faced with broken machines, the Lincos staff was often helpless because of the very limited means for communicating with the central office. One of the centers reported not having had any contact with Lincos officials for three months. A staff member indicated that "[the computers] all have problems, all of them do. But we don't have any resources to fix them and we can't get a technician to come here and fix them. [...] The Ethernet cards are wearing out on some of them, that's why we can't get Internet on some of them, but we can't replace them". They could not even reformat the computers because nobody knew where to find copies of the pre-installed software. And even if they did, staff members were afraid that they would not know how to use them. At most of the Lincos sites, limited financial resources and technical skills, and the dependency on external engineers, severely reduced their capacity for self-reliance; the poor communication between the centers and the officials was often the cause of frustration.

\section{Meaningful \& Transformational Usage}

When asked to explain the benefits of the computer labs, most people replied by mentioning that young people were now able to learn how to use a computer, an opportunity that did not exist before. When asked further why this was beneficial, answers were less easily forthcoming. When a response was given, it was typically that the youth would learn computer skills and in that way hopefully manage to obtain employment... preferably local employment. However, the Lincos communities with their very high unemployment rates generally suffer from their inhabitants fleeing to the cities in search of income opportunities. The Lincos project, even were it to succeed in teaching computer skills may actually expedite the process of out-migration. As one Lincos worker put it, "If you are in computers here, what can you do? There is nothing here!"

Lincos did exhibit ways of using its equipment in more self-sustainable ways, however. In one village, a young man who had spent several years working in a "Zona Franca" or "free trade zone" and was determined to never do so again, decided to make a garden out of his backyard in order to live off the consumption and selling of his crops. Knowing nothing about gardening, he borrowed an educational video from the local Lincos center and learned enough to get the crops going. This example may suggest a further element of the Lincos case - namely that the Lincos' benefits are dependent on individual initiatives while also contributing mainly to the advance of individuals rather than, as Lincos has stated as its ambition, to promote and become a natural part in the strategies supporting the advance of the community as a whole (see Lincos website).

The wish of many, however, was that the Lincos project and its anticipated result in developing computer-literate people, would help to attract businesses to the individual communities. A hope expressed in one of the villages was that a "Zona Franca" be established in the region. People who had learned 
computer skills at the Lincos would then be able to find employment in this free trade zone, it was suggested. Such a development would certainly be in line with the dominant vision of ICT-fordevelopment, which regards a nation's commercial growth as the primary source of development, and envisions ICT to be its motor. ICTs in this case would be used to marginally, and occasionally, improve the financial situation of occasional individuals but not to provide assistance in communitarian strategies towards structural social change.

\section{Conclusion}

This paper has attempted to provide a critical social perspective on a specific project but within the context of the broader use of ICTs as support for development. If and how citizens of marginalized communities should use ICTs are decisions that have to be made by these people themselves. Today, however, the dominant discourse informing such decision-making is deeply biased towards the excellence of Western technology - as the Lincos experience vividly demonstrates - and thus one important task of critical activists and investigators is to begin a process of exploring alternative understandings and strategies.

\section{References}

Badilla, E. S. (2001). El futuro de la educación: La decentralización del aprendizaje. [Transl.: "The future of Education: the Decentralization of Learning”]. Working paper (CR.3.024), Cambridge, MA: MIT Media Lab.

Benjamin, P., \& Dahms, M. (2001). Socialise the mode of production: The role of telecentres in development. In R. Gomez \& P. Hunt (Eds.), Telecentre evaluation: A global perspective. IDRC Report. Ottawa: IDRC.

Bjerknes, G., Pelle, E., \& Kyng, M. (1987). Computers and democracy: A Scandinavian challenge. Aldershot: Averbury.

Denscombe, M. (1998). The good research guide: for small-scale social research. Buckingham \& Philadelphia: Open University Press.

Ehn, P. (1988). Work-oriented design of computer artefacts. Stockholm: Arbetslivscentrum.

Escobar, A. (1994). Welcome to Cyberia. Current Anthropology, 35(3), 211-235.

Granqvist, M. (2003). Assessing ICT efforts in marginalized regions from a critical social viewpoint: Learning from the case of Lincos. Undergraduate thesis, Malmö University College. Available: http://www.funredes.org/olistica/documentos/thesismanne.pdf.

Heeks, R. (1999). The tyranny of participation in information systems: Learning from development projects. Working Paper. Manchester: Institute for Development Policy and Management.

Hoffman, B. (2002). Cómo no superar la brecha digital. Iberoamericana, 6, 181-185.

Howard, D. (1999). Dominican Republic: A guide to the people, politics and culture. New York: Interlink Publishing Group.

Latortue, P. (1999). Modern slavery: Neo-slavery in the cane fields, Haitians in the Dominican Republic. In C. Arthur \& M. Dash (Eds.), A Haiti anthology: Libète. London: Latin America Bureau.

Menou, M. (2001). IsICTometrics: Toward an alternative vision and process. Working paper, presented at RICYT \& Observatório das Ciências e das Tecnologias seminar on Indicators of the Information Society and Scientific Culture, Lisbon.

Mistica. (2002). Trabajando la Internet con una Vision Social. Collective document of the Mistica Virtual Community for the Olistica Project. Available: http://www.funredes.org/olistica/documentos/ 
Rahnema, M., \& Bawtree, V. (Eds.). (1997). The post-development reader. London: Zed Books.

Pfaffenberger, B. (1992). Technological dramas. Science, Technology \& Human Values, 17(3), 282-312.

Saunders, K. (Ed.). (2003). Feminist post-development thought: Rethinking modernity, post-colonialism \& representation. London: Zed Books.

World Bank (2002). Dominican Republic: Poverty assessment: Poverty in a high-growth economy (19862000). Poverty Reduction and Economic Management Unit, Latin America and the Caribbean, Report No 21306. Washington, DC: World Bank. 